\title{
Facility-Based Surveillance Activities for COVID-19 Infection and Outcomes among Healthcare Workers in a Nigerian Tertiary Hospital
}

\author{
Esohe O. Ogboghodo, ${ }^{1 \star}$ Iriagbonse I. Osaigbovo, ${ }^{2}$ Otaniyenuwa O. Obarisiagbon, ${ }^{1}$ Benson U. Okwara, ${ }^{3}$ Darlington E. Obaseki, ${ }^{4}$ \\ Orezimena T. Omo-lkirodah, ${ }^{1}$ Ewere S. Ehinze, ${ }^{1}$ Funmilola Adio, ${ }^{1}$ Joy C. Nwaogwugwu, ${ }^{1}$ and Efeomon F. Eseigbe ${ }^{1}$ \\ ${ }^{1}$ Department of Community Health, University of Benin Teaching Hospital, Benin City, Nigeria; ${ }^{2}$ Department of Medical Microbiology, University of \\ Benin Teaching Hospital, Benin City, Nigeria; ${ }^{3}$ Department of Medicine, University of Benin Teaching Hospital, Benin City, Nigeria; ${ }^{4}$ Office of the \\ Chief Medical Director/Department of Anatomic Pathology, University of Benin Teaching Hospital, Benin City, Nigeria
}

\begin{abstract}
COVID-19 in healthcare workers (HCWs) can result in nosocomial transmission, depletion in available workforce, and enhanced community transmission. This article describes surveillance for COVID-19 in HCWs at a tertiary healthcare facility, and documents the outcomes. A descriptive cross-sectional study of all HCWs identified from surveillance for COVID-19 from March 31 to August 31, 2020 was conducted. Healthcare workers were categorized as high risk and low risk using an adapted WHO Risk Assessment tool. Nasopharyngeal and oropharyngeal swab specimens obtained from high-risk subjects were tested by a reverse transcriptase PCR method. Data were analyzed with IBM SPSS version 25.0 software (IBM SPSS Statistics for Windows, Version 25.0, Armonk, NY), and results were presented as frequencies and percentages. The level of significance was set at $P<0.05$. During 5 months of surveillance, 1,466 HCWs with a mean age of $38.1 \pm 9.7$ years were identified as contacts. On risk assessment, $328(22.4 \%)$ were adjudged high risk. High risk was associated with increasing age $(P<0.001)$, male gender $(P=0.001)$, and nonclinical staff $(P=0.002)$. Following testing, $78(5.3 \%)$ in the high-risk category were confirmed to have COVID-19. There was no record of COVID19 in HCWs adjudged low risk. Forty-four (56.4\%) cases were epidemiologically linked to the community, 20 (25.7\%) to patients, and $14(17.9 \%)$ to another HCW. Surveillance and risk assessment are crucial to COVID-19 response in healthcare facilities and revealed HCW infections with predominantly nonoccupational epidemiological links in this study.
\end{abstract}

\section{INTRODUCTION}

The COVID-19 pandemic has exerted immense pressure on health systems worldwide saddling many with the enormous task of dual-tracking health services by ensuring the provision of regular care while simultaneously addressing COVID-19 case management. ${ }^{1,2}$ Administrators of healthcare facilities are duty-bound to protect healthcare workers (HCWs) from contracting the disease by ensuring proper training in infection prevention and control (IPC) and adequate supply of personal protective equipment (PPE). ${ }^{3}$ Beyond the direct effects of illhealth, failure to prevent COVID-19 in HCWs has other farreaching consequences. Infected health workers, if not detected early and removed from the line of duty, serve as potential agents of disease transmission to vulnerable patients within hospitals. ${ }^{4}$ Nosocomial spread may become particularly marked because of the high rates of asymptomatic/ presymptomatic transmission linked with COVID-19 and presenteeism typically displayed by healthcare workers. ${ }^{4-6}$ In addition, uncontrolled rates of HCW infection with the resultant abstinence from work could result in overwhelming manpower shortages that can cripple routine service delivery and COVID-19 case management in healthcare facilities. ${ }^{1,7}$ Furthermore, infected HCWs can transmit the disease to close family contacts, other $\mathrm{HCWs}$, and the community, thereby worsening the pandemic. ${ }^{1,8}$

To protect HCWs and prevent secondary transmission within hospitals and the community, it is imperative that healthcare facilities implement clear strategies to identify, support, and adequately manage exposed and infected personnel. ${ }^{9,10}$ These strategies constitute facility-based disease surveillance, one of the WHO's eight core components of

* Address correspondence to Esohe O. Ogboghodo, Department of Community Health, University of Benin Teaching Hospital, Benin Lagos Express Road, Ugbowo 300283, Benin City PMB1111, Nigeria. E-mail: oliviadynski@yahoo.com
IPC. ${ }^{11}$ Surveillance is the process of systematic collection, collation, and analysis of data with prompt dissemination to those who need to know, for relevant action to be taken. A well-functioning disease surveillance system provides information for planning, implementation, monitoring, and evaluation of public health intervention programmes. ${ }^{12}$ During the COVID-19 pandemic, various surveillance strategies have been adopted to detect HCW infection including voluntary or mandatory self-monitoring and reporting of symptoms among HCWs; institution of diagnostic testing for symptomatic HCWs and periodic testing among frontline workers managing confirmed COVID-19 cases even when asymptomatic; and contact tracing. ${ }^{1,4,10,13}$ Irrespective of the strategy used, defining the risk of an HCW being infected with SARS-CoV-2 which causes COVID-19 is often the first step in selecting the most appropriate approach for monitoring and evaluation. ${ }^{10}$ Risk categories for inhospital exposures depend on the type of contact that has taken place, whether PPE was used consistently and appropriately, presence during aerosol-generating procedures, and level of distancing from patients with COVID-19. ${ }^{10,14}$ Standardized protocols for risk assessment have been formulated by the WHO and other national and international bodies to categorize HCWs based on exposure to confirmed cases and to develop precise recommendations based on the level of exposure. ${ }^{15-18}$ Technology in the form of real-time location systems and closedcircuit television cameras in patient care areas can also aid the execution of risk assessments, but this is capital-intensive and unfeasible in resource-constrained settings. ${ }^{12,19}$

Low and middle-income regions have been disproportionately affected by the global shortages in medical consumables and equipment occasioned by the COVID-19 pandemic. $^{20}$ This has worsened the inherent gaps in response capacity, IPC, PPE availability, and HCW number, which characterizes African healthcare settings. ${ }^{21}$ Healthcare worker vulnerability to COVID-19 in these settings is projected to be great and has the potential to drive nosocomial infection rates, worsening 
the pandemic. ${ }^{21}$ The need for surveillance specifically targeted at identifying infected HCWs can therefore not be overemphasized. Despite this, there remains a paucity of information on facility-based surveillance activities for COVID19 in HCWs in the African, and specifically, Nigerian context. This study aimed to describe surveillance for COVID-19 infections in HCWs and the outcome of these activities in a tertiary hospital in Edo state, Southern Nigeria.

\section{MATERIALS AND METHODS}

Study area. This descriptive cross-sectional study was conducted in the University of Benin Teaching Hospital (UBTH), Benin City, Edo state, in Southern Nigeria. This 860-bed facility renders promotive, preventive, curative, and rehabilitative services in various departments, including internal medicine, surgery, pediatrics, mental health, community health, obstetrics and gynecology, radiology, ear, nose and throat, anesthesiology, ophthalmology, family medicine, and dentistry. ${ }^{22,23}$ The UBTH currently has a staff strength of 4,220 .

The UBTH is one of the three public hospitals designated as an isolation facility for the management of COVID-19 patients by the Edo state government. The isolation infrastructure in the hospital is composed of a 24-bed isolation ward, an 18bed isolation annex for asymptomatic and mild cases, a 2-bed level III intensive care unit dedicated to COVID-19 patients, and an 18-bed holding bay for suspected COVID-19 cases. The UBTH also houses one of three molecular testing laboratories in the state accredited by the Nigeria CDC (NCDC) for diagnosis of COVID-19 by real-time reverse transcriptase PCR. The first two COVID-19 cases in the facility were recorded on March 31, 2020. ${ }^{24}$

Before the COVID-19 pandemic, the management instituted a hospital-wide IPC education campaign on standard precautions through its IPC committee. Handwashing and waste management facilities were upgraded, and water, a major determinant for sanitation especially in resource-limited settings, was made available at all times. At the start of the pandemic in Nigeria, the management constituted a COVID19 response team comprising seven pillars, namely, central co-ordination and research, logistics, communication, case management, diagnostic, screening and triage, and IPC/ surveillance. These pillars had specific terms of reference aimed at overseeing the response to COVID-19 in the hospital. A risk stratification tool was adapted to identify vulnerable staff who were re-deployed to nonclinical areas or asked to work from home. ${ }^{23}$ In addition to increasing the purchase and availability of face masks, gloves, and eye goggles (necessary for standard precautions and transmission based precautions), relevant hospital departments embarked on the local production of plastic aprons, coveralls, and face shields. Also, information education and communication posters on COVID19 were placed at strategic locations, and advisories were regularly communicated to staff. A "No face mask No entry" policy was subsequently adopted to mitigate the spread of COVID-19 within the facility. ${ }^{24}$

Study population. A total population study of all HCWs identified through passive/syndromic and active surveillance within the hospital between March 31 and August 31, 2020 was conducted. An HCW was defined as any member of staff in the healthcare facility involved in the provision of care for a COVID-19 patient, including those who have been present in the same area as the patient and those who may not have provided direct care to the patient but who have had contact with the patient's body fluids, potentially contaminated items or environmental surfaces. This included healthcare professionals, allied health workers, and auxiliary health workers such as cleaning and laundry personnel, X-ray physicians and technicians, clerks, phlebotomists, respiratory therapists, nutritionists, social workers, physical therapists, laboratory personnel, cleaners, admission/reception clerks, patient transporters, and catering staff. ${ }^{25}$

Infection prevention and control/surveillance activities. The IPC/surveillance pillar consisted of a head and team members from the facility's IPC committee with specific terms of reference including conducting surveillance for COVID-19 in HCWs. The team liaised with the communications pillar to encourage staff to self-assess for symptoms of COVID-19 and report such symptoms. Core activities included line-listing, contact tracing, performing risk assessments of exposed staff, and determining epidemiological links. Reporting of exposure to cases of COVID-19 outside the workplace was also encouraged, and risk assessment was also conducted for these staff. In addition, a line of communication was established with the diagnostic pillar to promptly notify the IPC/surveillance pillar of all laboratoryconfirmed cases of COVID-19 in hospitalized patients and HCWs within the facility.

Data collection. The tool for data collection was an interviewer administered NCDC COVID-19 contact tracing form. ${ }^{26}$ Risk assessment was conducted using a tool adapted from the WHO risk assessment and management of exposure of health care workers in the context of COVID-19: interim guidance. ${ }^{15}$ This tool is used by healthcare facilities that have either admitted or cared for COVID-19 patients and is completed for all health workers who have been exposed to a confirmed COVID-19 patient. It enabled the assessment of HCW activities performed on COVID-19 patients in healthcare facilities, adherence to IPC procedures during healthcare interactions, and adherence to IPC measures when performing aerosol-generating procedures (e.g., tracheal intubation, nebulizer treatment, open airway suctioning, collection of sputum, tracheotomy, bronchoscopy, and cardiopulmonary resuscitation). Responses were assessed on a Likert scale, with choices "always, as recommended," "most of the time," "occasionally," and "rarely." Healthcare workers who did not respond "always, as recommended" were categorized as high risk. ${ }^{15}$ Documentation was carried out by surveillance team members, who served as research assistants for the purpose of this study.

All HCWs who were adjudged high risk were tested, regardless of whether or not they were symptomatic. Nasopharyngeal and oropharyngeal swabs were collected from HCWs in the high-risk category for diagnostic testing for SARS-CoV-2 by real-time RT-PCR at the molecular virology laboratory. Testing was conducted on day 5-7 following last contact with the COVID-19 case to ensure a high yield. Results were fed back to the team for collation and appropriate action.

Data analysis. Data were entered into IBM SPSS version 25.0 and analyzed. The statistical measures for the quantitative analysis were means with SDs for continuous variables, and absolute numbers with percentage frequencies for categorical variables. The level of significance was set at $P<0.05$ for all statistical associations. Frequency tables were used to present the results. 
Ethical considerations. Ethical approval was obtained from the Ethics and Research Committee of the UBTH.

\section{RESULT}

During the 5-month surveillance period, a total of 1,466 $\mathrm{HCWs}$, representing $34.7 \%$ of the total workforce in the UBTH $(N=4,220)$, reported symptoms or were exposed to COVID-19 infection. Their sociodemographic characteristics are shown in Table 1. The mean age of the HCWs was $38.1 \pm 9.7$ years, and $1,080(73.7 \%)$ were in the 20 - to 39-year age-group. Healthcare workers aged 60 years and older made up the least proportion of HCWs exposed at six (0.4\%). Eight hundred thirty-two of the exposed HCWs (56.8\%) were female (Table 1). A higher proportion of HCWs exposed (741, 50.5\%) were doctors, and over half $(783,53.4 \%)$ resided in Egor Local Government Area of Edo state (Table 1).

Following risk assessment for COVID-19, 328 (22.4\%) $\mathrm{HCW}$ were adjudged to be high risk. With increasing age, the proportion of high-risk contacts among HCWs increased, with the age-group $>60$ years having the highest proportion (5, $83.3 \%$ ) of high risk for COVID-19. The association between age and risk assessment for COVID-19 was statistically significant $(P<0.001)$. More male HCWs $(173,27.3 \%)$ were in the high-risk category. The association between gender and risk assessment for COVID-19 infection was also statistically significant $(P<0.001)$. A higher proportion of HCWs in the high-risk category were in the "other" staff category (laundry personnel, X-ray technicians, phlebotomists, nutritionists, social workers, physical therapists, laboratory personnel, cleaners, porters, and catering staff), whereas the least proportion five (12.2\%) were paramedics. The association between profession of HCWs and risk assessment was statistically significant $(P=0.002)$ (Table 2).

Seventy-eight HCWs in the high-risk group were positive for COVID-19 infection following testing, representing 5.3\% ( $n=$

TABLE 1

Sociodemographic characteristics of healthcare workers exposed to COVID-19

\begin{tabular}{lrr}
\hline \multicolumn{1}{c}{ Variable } & Frequency $(n=1,466)$ & Percent \\
\hline Age (years) & 1,080 & \\
$20-39$ & 380 & 25.7 \\
$40-59$ & 6 & 0.4 \\
$\geq 60$ & 634 & 43.2 \\
Gender of HCWs & 832 & 56.8 \\
Male & & \\
Female & 741 & 50.5 \\
Cadre of HCWs & 564 & 38.5 \\
Doctors & 41 & 2.8 \\
Nurses & 55 & 3.8 \\
Paramedic & 22 & 1.5 \\
Health assistants & 43 & 2.9 \\
Administrative staff & & \\
Others & & \\
Local government area of residence of & 783 & 53.4 \\
HCWs & 297 & 20.3 \\
$\quad$ Egor & 286 & 19.5 \\
Ovia north east & 87 & 5.9 \\
Oredo & 13 & 0.9 \\
$\quad$ Ikpoba-Okha & \\
$\quad$ Uhunmwonde & \\
\hline
\end{tabular}

HCWs = healthcare workers. nutritionists, social workers, physical therapists, laboratory personnel, cleaners, porters, and catering staff.
$1,466)$ of HCWs identified by surveillance, $1.8 \%(N=4,220)$ of all workers in the facility, and $20.4 \%(n=383)$ of COVID-19 diagnoses made in the facility within the same reporting frame. Table 3 shows the sociodemographic characteristics of infected HCWs. Their mean age was $34.6 \pm 11.0$ years, with 52 $(66.7 \%)$ in the 20 - to 39 -year age-group, and 41 (52.6\%) were male. Forty-five (57.7\%) were doctors, a higher proportion of whom $(25,32.1 \%)$ were resident doctors. There was no travel history in 77 (98.7\%) of infected HCWs. Attack rates among the various cadres were $3.2 \%$ in nurses, $6.1 \%$ in doctors, $7.3 \%$ in health assistants, $9.8 \%$ in paramedics, and $12.3 \%$ in others. Table 4 shows surveillance activities and epidemiological link of disease exposure of the infected workers. Although 33 (42.3\%) were identified through active surveillance activities, 42 (53.9\%) HCWs voluntarily self-reported symptoms of COVID-19. Epidemiological link of disease exposure of the infected workers revealed that 44 (56.4\%) were linked to the community, $20(25.7 \%)$ were linked to patients, and 14 (17.9\%) were linked to other HCWs in the facility. Figure 1 depicts the weekly number of new cases of COVID-19 in HCWs in the UBTH from March 31, 2020 to August 31, 2020, with the highest number of new cases (12) recorded in the 13th week.

\section{DISCUSSION}

Surveillance is the continuous scrutiny for occurrence of disease and health-related events through systematic collection, analysis, and interpretation of data closely integrated with the timely dissemination of these data to enable prompt intervention. ${ }^{27,28}$ In the UBTH, passive/syndromic (self-reporting) and active (monitoring, outbreak investigation, and contact tracing) surveillance approaches were combined with risk assessment to identify HCWs at high risk of contracting COVID-19, followed by diagnostic testing of high-risk subjects at the on-site molecular virology laboratory to confirm those who were actually infected. The outcome of surveillance activities during the 5-month period was the detection of 78 cases of COVID-19 in HCWs, which represented $1.8 \%$ of the total workforce, $5.3 \%$ of those identified by surveillance, and $20.4 \%$ of all COVID-19 cases diagnosed in the hospital. Epidemiological links to patients, other HCWs, and household and community contacts were also established.

Although concerns about COVID-19 infections in HCWs largely centered on shortages in the supply of PPE and occupational exposure to confirmed patients in the early days of the pandemic, studies have increasingly emphasized other routes of transmission. ${ }^{29-33}$ Less than $30 \%$ of infections in the index study were epidemiologically linked to patient care. With proper use of PPE and good adherence to IPC measures, the risk of SARS-CoV-2 infection of HCWs caring for COVID-19 patients is expected to be low. ${ }^{10}$ Accordingly, the hospital management went to great lengths to secure PPE for staff during the period to the extent of venturing into indigenous production of gowns, face masks, and face shields to complement supply. In addition, the IPC/surveillance pillar provided health education on standard precautions and appropriate use of PPE to all cadres of staff. The fact that no HCW infection was detected among the staff manning the COVID-19 isolation ward may imply strict compliance with PPE use and IPC measures in that section of the facility.

Interestingly, an epidemiological link with ongoing community transmission was established in more than half of 
TABLE 2

Sociodemographic characteristics and risk assessment category for COVID-19

\begin{tabular}{|c|c|c|c|c|}
\hline \multirow[b]{2}{*}{ Variable } & \multicolumn{2}{|c|}{ Risk assessment category $(n=1,466)$} & \multirow[b]{2}{*}{ Test statistics } & \multirow[b]{2}{*}{$P$-value } \\
\hline & High $(n=328)$ Frequency $(\%)$ & Low $(n=1,138)$ Frequency $(\%)$ & & \\
\hline \multicolumn{5}{|l|}{ Age (years) } \\
\hline $20-39$ & $214(19.8)$ & $866(80.2)$ & - & - \\
\hline $40-59$ & $109(28.7)$ & 271 (71.3) & $x^{2}=25.622$ & $P<0.001$ \\
\hline$\geq 60$ & 5 (83.3) & $1(16.7)$ & $n-$ & - \\
\hline \multicolumn{5}{|l|}{ Gender } \\
\hline Male & 173 (27.3) & $461(72.7)$ & $x^{2}=15.527$ & $P=0.001$ \\
\hline Female & $155(18.6)$ & $677(81.4)$ & - & - \\
\hline \multirow{2}{*}{\multicolumn{5}{|c|}{$\begin{array}{l}\text { Occupational groups of healthcare } \\
\text { workers }\end{array}$}} \\
\hline & & & & \\
\hline Doctors & $182(24.6)$ & $559(75.4)$ & $x^{2}=19.294$ & $P=0.002$ \\
\hline Nurses & $104(18.4)$ & $460(81.6)$ & - & - \\
\hline Others ${ }^{*}$ & 17 (39.5) & $26(60.5)$ & - & - \\
\hline Health assistants & $12(21.8)$ & 43 (78.2) & - & - \\
\hline Administrative staff & $8(36.4)$ & $14(63.6)$ & - & - \\
\hline Paramedics & $5(12.2)$ & $36(87.8)$ & - & - \\
\hline
\end{tabular}

infected HCWs. Furthermore, the epidemic curve of HCW infection closely mirrored the general epidemic curve in the state. Zheng et al. ${ }^{29}$ made similar observations in a study of HCW infections in a London teaching hospital, and several other studies in countries such as the Netherlands, Australia, and the United States have documented links between COVID19 in HCWs and ongoing community transmission. ${ }^{30-32}$ The consensus on the dominant role played by community transmission buttresses the fact that HCWs face dual risk of infection during a pandemic, calls for more emphasis on protecting them through education and provision of services that prevent undue exposure in the community.

Transmission of COVID-19 from one HCW to other HCWs is another understated mode of infection in $\mathrm{HCWs}^{33}$ In this study, it accounted for close to one in five cases detected. Although

TABLE 3

Sociodemographic characteristics of infected healthcare workers

\begin{tabular}{lcc}
\hline \multicolumn{1}{c}{ Variable } & Frequency $(n=78)$ & Percent \\
\hline Age (years) & & \\
$20-39$ & 52 & 66.7 \\
$40-59$ & 26 & 33.3 \\
$\geq 60$ & 0 & 0.0 \\
Mean \pm SD $=34.6 \pm 11.0$ & & \\
Sex & & \\
Male & 41 & 52.6 \\
Female & 37 & 47.4 \\
Occupational groups of healthcare & & \\
workers & & \\
Doctors & & \\
$\quad$ House officers & 16 & 20.5 \\
$\quad$ Resident doctors & 25 & 32.1 \\
$\quad$ Consultants & 4 & 5.1 \\
$\quad$ Nurse & 18 & 23.1 \\
Paramedics & 4 & 5.1 \\
Health assistant & 3 & 3.9 \\
Radiographer & 2 & 2.6 \\
Laboratory scientist & 2 & 2.6 \\
Admin staff & 1 & 1.3 \\
Pharmacist & 1 & 1.3 \\
Technician & 1 & 1.3 \\
Physiotherapist & 1 & 1.3 \\
Travel history & & \\
Yes & 1 & 1.3 \\
No & 77 & 98.7 \\
\hline
\end{tabular}

physical meetings were halted as part of hospital policy during the pandemic, physical distancing may not have been fully observed in office spaces and during meals where close contact can be made with colleagues. ${ }^{10}$ In a case-control study in Turkey, besides inappropriate use of PPE while caring for patients, significant risk factors for infection in $\mathrm{HCW}$ s included staying in the same personal break room with an infected $\mathrm{HCW}$ without a medical mask for more than 15 minutes, consuming food within $1 \mathrm{~m}$ of an infected HCW, and failure to keep a safe distance from an infected $\mathrm{HCW}^{34}$ In a retrospective account from Spain, systematic use of face masks, prohibition of shared meals, and institution of physical distancing in the refectory were followed by a decline in the number of HCW infections. ${ }^{33}$ The observation of HCW-to-HCW infections in the UBTH necessitated an advisory from management reiterating the mandatory use of face masks by HCWs in all areas of the hospital including administrative offices. Many offices and departments likewise adopted signage that precluded entry without a face mask.

Early screening, testing, and isolation of infected HCWs in the UBTH helped achieve the primary target of preventing the spread of COVID-19 to patients and other HCWs. The benefits of surveillance however did not end there. Being able to directly measure what goes on in a population, surveillance is useful both for measuring the need for interventions and for directly measuring the effects of interventions. ${ }^{35}$ Thus, besides identifying infected $\mathrm{HCW}$ s and reducing the occurrence of nosocomial spread by ensuring that they stayed away from work, the results of surveillance and risk assessment in the facility helped identify gaps in attitude and practice of IPC and PPE use among staff. This led to focused behavioral change

TABLE 4

Mode of surveillance and epidemiological links among COVID-19infected healthcare workers

\begin{tabular}{lcr}
\hline \multicolumn{1}{c}{ Variable } & Frequency $(n=78)$ & Percent \\
\hline Surveillance activities & & \\
Passive/syndromic & 42 & 53.9 \\
Active & 33 & 42.3 \\
Family contact & 3 & 3.8 \\
Epidemiological link & 42 & \\
Community exposure & 21 & 26.9 \\
Patient & 15 & 19.2 \\
Other healthcare workers & & \\
\hline
\end{tabular}




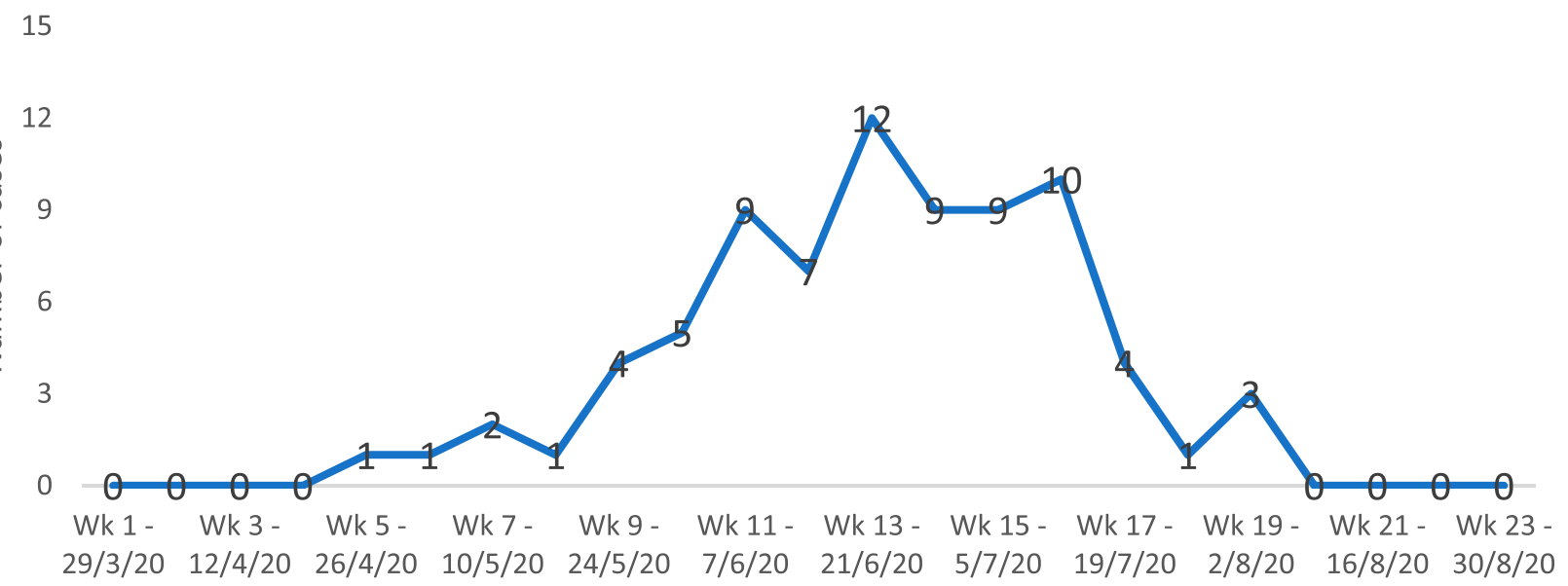

Week

FIGURE 1. Epidemic curve showing the number of new cases of healthcare workers with COVID-19 from March 31 to August 31, 2020. This figure appears in color at www.ajtmh.org.

communication and health educational activities among targeted staff by the IPC/surveillance team. For instance, although a higher proportion of HCW infections occurred in doctors and nurses, attack rates in these cadres were less than those in health assistants and paramedics. On closer scrutiny, it became clear that health assistants possibly complied poorly with IPC although a cluster of infections among paramedics was linked with their communal living arrangements. The health talks in these two groups differed substantially emphasizing rational and appropriate PPE use during work for the former and harping on social distancing and use of face masks even when with colleagues to the latter. Healthcare workers were also educated on the need to adopt community mitigation strategies when outside the workplace as the tendency to acquire the infection from household and community contacts was high across all cadres. By stratifying staff exposed as low risk, they were able to return to work promptly with symptom monitoring, thereby preventing manpower shortages. In testament to the effectiveness of efficiently deployed risk assessment tools, no $\mathrm{HCW}$ s stratified as low risk came down with symptoms of COVID19. Finally, the targeted deployment of testing resources to the high-risk category helped conserve resources including sampling swabs and transport medium as well as PCR test kits. Risk assessment and monitoring also provided reassurance for worried staff and engendered trust in the workplace as employees were convinced of management's concern for their welfare. This led to a boost in morale and employee satisfaction.

Despite the intensive surveillance activities, HCW infection in the UBTH may still have been underestimated for a number of reasons. First, some symptomatic HCWs, especially the mildly symptomatic, may have deliberately refused to report symptoms and access testing because of fear or stigma. For instance, the lower incidence of HCW infection in nonclinical staff categories in the UBTH could be due to a particularly low rate of self-reporting among this group. The very low rate of infection among nonclinical staff in this study contrasts sharply with findings from other studies which show substantial rate of infection in HCWs performing jobs that did not involve direct patient care; in some instances, no difference in rates was discernible between frontline staff such as nurses, doctors and allied healthcare professionals, and nonclinical staff including clerical, administrative and information technology staff. ${ }^{33,36}$ Second, reporting bias in HCWs being assessed may have compromised the accuracy of risk assessment. However, part of the risk assessment strategy was to corroborate the account from the HCWs under investigation with accounts from other colleagues on the team and those present at the scene of exposure. Finally, there is the possibility of falsely negative RT-PCR result if the test is conducted too early. To minimize the impact of this, asymptomatic $\mathrm{HCW}$ who had a negative result were asked to report the development of symptoms within 14 days of taking the test, and none of them developed symptoms. In the long run, the true extent of HCW infection may only be made apparent when surveillance studies are undertaken using reliable serological assays.

In conclusion, outcomes of surveillance in the index facility have revealed that while occupational exposure constituted a risk to HCWs, they were more at risk of contracting COVID-19 from colleagues in the workplace, family, and other members of the community. Thus, risk communication was comprehensive and encouraged IPC and other protective behaviors both within and outside the work environment. The study showed that building capacity for surveillance is a worthwhile investment as healthcare facilities must incorporate HCW infection surveillance in their response plan for infectious disease pandemics.

Received October 29, 2020. Accepted for publication January 11, 2021.

Published online January 20, 2021.

Acknowledgments: We wish to thank the surveillance unit of the University of Benin Teaching Hospital. The American Society of Tropical Medicine and Hygiene has waived the Open Access fee for this article due to the ongoing COVID-19 pandemic and has assisted with publication expenses.

Financial support: This research was self-sponsored by authors.

Authors' addresses: Esohe O. Ogboghodo, Otaniyenuwa O. Obarisiagbon, Orezimena T. Omo-lkirodah, Ewere S. Ehinze, Funmilola Adio, Joy C. Nwaogwugwu, and Efeomon F. Eseigbe, Department of Community Health, University of Benin Teaching Hospital, Benin City, Nigeria, E-mails: oliviadynski@yahoo.com, otasobas@gmail.com, 
orezito@yahoo.co.uk, ewere.scholar1@gmail.com, adiofunmi@ gmail.com, nwaogwugwu.cp@gmail.com, and efeomon@gmail.com. Iriagbonse I. Osaigbovo, Department of Medical Microbiology, University of Benin Teaching Hospital, Benin City, Nigera, E-mail: iyabo.osaigbovo@uniben.edu. Benson U. Okwara, Department of Medicine, University of Benin Teaching Hospital, Benin City, Nigeria, E-mail: bensonokwara81@gmail.com. Darlington E. Obaseki, Office of the Chief Medical Director/Department of Anatomic Pathology, University of Benin Teaching Hospital, Benin City, Nigeria, E-mail: darlobaseki@gmail.com.

This is an open-access article distributed under the terms of the Creative Commons Attribution (CC-BY) License, which permits unrestricted use, distribution, and reproduction in any medium, provided the original author and source are credited.

\section{REFERENCES}

1. Black JRM, Bailey C, Przewrocka J, Dijkstra KK, Swanton C, 2020. COVID-19: the case for healthcare worker screening to prevent hospital transmission. Lancet 395: 1418-1420.

2. World Health Organization. Strengthening and Adjusting Public Health Measures Thoughout the COVID-19 Transition Phases. Available at: https://www.euro.who.int/_data/assets/pdf_file/ 0018/440037/Strength-AdjustingMeasuresCOVID19-transitionphases.pdf?ua=1. Accessed October 2, 2020.

3. World Health Organization, 2020. Coronavirus Disease (COVID19) Outbreak: Rights, Roles and Responsibilities of Health Workers Including Key Considerations for Occupational Safety and Health. Available at: https://www.who.int/docs/defaultsource/coronaviruse/who-rights-roles-respon-hw-covid-19.pdf? sfvrsn=bcabd401 0. Accessed October 5, 2020.

4. Wee LE, Sim XYJ, Conceicao EP, Aung MK, 2020. Containment of COVID-19 cases among healthcare workers: the role of surveillance, early detection, and outbreak management. Infect Control Hosp Epid 41: 765-771.

5. Wang Y, Chen Y, Qin Q, 2020. Unique epidemiological and clinical features of the emerging 2019 novel coronavirus pneumonia (COVID-19) implicate special control measures. J Med Virol 92: 568-576.

6. Webster RK, Liu R, Karimullina K, Hall I, Amlôt R, Rubin GJ, 2019. A systematic review of infectious illness presenteeism: prevalence, reasons and risk factors. BMC Public Health 19: 799.

7. Mhango M, Dzobo M, Chitungo I, Dzinamarira T, 2020. COVID-19 risk factors among health workers: a rapid review. Saf Health Work 11: 262-265.

8. Adams JG, Walls RM, 2020. Supporting the healthcare workforce during the COVID-19 global epidemic. JAMA 323: 1439-1440.

9. ECDC, 2020. Infection Prevention and Control for COVID-19 in Healthcare Settings-Second Update, 31 March 2020. Stockholm, Sweden: ECDC. Available at: https://www.ecdc.europa.eu/ sites/default/files/documents/Infection-prevention-control-forthe-care-of-patients-with-2019-nCoV-healthcare-settings update-31-March-2020.pdf. Accessed October 2, 2020.

10. Bielicki JA, Duval X, Gobat N, Goossens H, Koopmans M, Tacconelli E, van der Werf S, 2020. Monitoring approaches for health-care workers during the COVID-19 pandemic. Lancet Infect Dis 20: e261-267.

11. CDC, 2020. Operational Considerations for the Identification of Healthcare Workers and Inpatients with Suspected COVID-19 in Non-US Healthcare Settings. Available at: cdc.gov/ coronavirus/2019-ncov/hcp/non-us-setting/guidance-identifyhcw-patients.html. Accessed October 2, 2020.

12. World Health Organization, 2020. Protocol for the Assessment of National Communicable Disease Surveillance and Response Systems. WHO/CDS/CSR/ISR/2001.2. Available at: https://www.who.int/csr/resources/publications/surveillance/ whocdscsrisr20012.pdf. Accessed October 2, 2020.

13. Mehta N, Vehdala K, Swaim S, Welch S, Calender A, Kakkera K et al., 2020. Identifying asymptomatic healthcare workers with COVID-19 in a community hospital: an institution's experience. J Community Hosp Intern Med Perspect 10: 396-398.

14. Shrivastava SR, Shrivastava PS, 2020. Standardised risk assessment and management of exposure amongst healthcare workers to coronavirus disease 2019. Germs 10: 126-128.
15. World Health Organization, 2020. Risk Assessment and Management of Exposure of Health Care Workers in the Context of COVID-19. Available at: https://www.who.int/publications/m/ item/risk-assessment-and-management-of-exposure-ofhealth-care-workers-in-the-context-of-covid-19-data-template. Accessed October 5, 2020.

16. European CDC, 2020. Contact Tracing: Public Health Management of Persons, Including Healthcare Workers, Having Had Contact with COVID-19 Cases in the European Union. Available at: https://www.ecdc.europa.eu/sites/default/files/documents/ covid-19-public-health-management-contact-novel-coronaviruscases-EU.pdf. Accessed October 15, 2020.

17. CDC, 2020. Interim US Guidance for Risk Assessment and Public Health Management of Healthcare Personnel with Potential Exposure in a Healthcare Setting to Patients with Coronavirus Disease (COVID-19). Available at: https://www.cdc.gov/ coronavirus/2019-ncov/hcp/guidance-risk-assessment-hcp.html. Accessed October 15, 2020.

18. Ho HJ, Lim W, Ang B, Chow A, 2020. Use of surveillance technology to enhance exposure management for healthcare workers during the COVID-19 pandemic. J Hosp Infect 107: 101-102.

19. Ho HJ, Zhang ZX, Huang Z, Aung AH, Lim W, Chow A, 2020. Use of a real-time locating system for contact tracing of health care workers during the COVID-19 pandemic at an infectious disease centre in Singapore: validation study. J Med Internet Res 22: e19437.

20. McMahon DE, Peters GA, Ivers LC, Freeman EE, 2020. Global resource shortages during COVID-19: bad news for lowincome countries. PLoS Negl Trop Dis 14: e0008412.

21. Cherisch MF et al., 2020. COVID-19 in Africa: care and protection for frontline healthcare workers. Global Health 16: 46.

22. University of Benin Teaching Hospital, 2020. General information. Available at: https://ubth.org/general-information/. Accessed October 2, 2020

23. Obaseki DE, Akoria OA, Mokogwu N, Omuemu CE, Okwara BU, Ogboghodo EO, 2020. Staff risk stratification in preparation for COVID-19 in a tertiary healthcare facility in Nigeria. Pan Afr Med J 35: 124.

24. Okwara BU, Ogboghodo EO, Osaigbovo II, Obaseki DE, Omuemu CE, Oduware E, Osemwenkhai M, 2020. An analysis of COVID19 patients receiving care in a tertiary facility in Southern Nigeria. West Afr J Med 37: 715-720.

25. World Health Organization, 2020. Assessment of Risk Factors for Coronavirus Disease 2019 (COVID-19) in Health Workers: Protocol for a Case-Control Study. Available at: https://www.who.int/ publications/i/item/assessment-of-risk-factors-for-coronavirusdisease-2019-(covid-19)-in-health-workers-protocol-for-a-casecontrol-study. Accessed October 2, 2020.

26. Nigeria CDC, 2020. COVID-19 Contact Line-Listing Form. Available at: https://ncdc.gov.in/WriteReadData/l892s/ 52892177941586772139.pdf. Accessed October 2, 2020.

27. Thacker SB, Berkelman RL, 1988. Public health surveillance in the United States. Epidemiologic Rev 10: 164-190.

28. Buehler JW, Hopkins RS, Overhague JM, Sosin DM, Tong V, CDC Working group, 2004. Framework for evaluating public health surveillance systems for early detection of outbreaks: recommendations from the CDC Working Group. MMWR Recomm Rep 53: 1-11.

29. Zheng C, Hafezi-Bakhtiari N, Cooper V, Davidson H, Habibi M, Riley P, Breathnach A, 2020. Characteristics and transmission dynamics of COVID-19 in healthcare workers at a London teaching hospital. J Hosp Infect 106: 325-329.

30. CDC COVID-19 Response Team, 2020. Characteristics of healthcare personnel with COVID-19 United States, February 12-April 9, 2020. MMWR Morb Mortal Wkly Rep 69: 487-481.

31. Reusken CB et al., 2020. Rapid assessment of regional SARSCoV-2 community transmission through a convenience sample of healthcare workers, The Netherlands, March 2020. Euro Surveill 25: 2000334.

32. Muhi S, Irving LB, Buising KL, 2020. COVID-19 in Australian health care workers: early experience of the Royal Melbourne emphasizes the importance of community acquisition. Med J Aust 213: 44. 
33. Suárez-García I, Martínez de Aramayona López MJ, Sáez Vicente A, Lobo Abascal P, 2020. SARS-CoV-2 infection among healthcare workers in a hospital in Madrid, Spain. J Hosp Infect 106: 357-363.

34. Çelebi G, Pişkin N, Bekleviç AÇ, Altunay Y, Keleş AS, Tüz MA, Altınsoy B, Hacıseyitoğlu D, 2020. Specific risk factors for SARS-CoV-2 transmission among health care workers in a university hospital. Am J Infect Control 48: 1225-1230.
35. Nsubuga $P$ et al., 2006. Public health surveillance: a tool for targeting and monitoring interventions. Jamison DT et al., eds. Disease Control Priorities in Developing Countries, 2nd edition. Washington, DC and New York, NY: The Intemational Bank for Reconstruction and Development/The World Bank and Oxford University Press. Chapter 53. Available at: https://www.ncbi.nlm.nih.gov/books/NBK11770/.

36. Hunter E et al., 2020. First experience of COVID-19 screening of health-care workers in England. Lancet 395: E77-E78. 